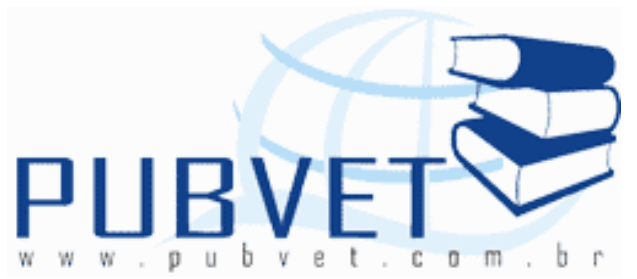

PUBVET, Publicações em Medicina Veterinária e Zootecnia.

\title{
Caracterização climática e o efeito do estresse hídrico sob as plantas nativas da caatinga
}

\section{Mariah Tenorio de Carvalho Souza ${ }^{1}$, Márcio Eduardo Freire Silva ${ }^{2}$, Paula}

Frassinetti Medeiros de Paulo ${ }^{1}$, Adelílian Baracho Ribeiro3 ${ }^{3}$ Alberício Pereira de Andrade $^{4}$, Meiry Rodrigues Cassuce ${ }^{5}$

1 Discentes do curso Doutorado Integrado em Zootecnia da Universidade Federal da Paraíba. Centro de Ciências Agrárias. CCA/UFPB. Campus II Rodovia BR 079 - Km 12, Areia - PB. CEP: 58.397-000. Autor para correspondência: email: mariah tenorio@hotmail.com, paula.frssntt@hotmail.com

${ }^{2}$ Discente do curso de graduação em Agronomia da Universidade Federal da Paraíba. Centro de Ciências Agrárias. CCA/UFPB. Campus II - Rodovia BR 079 Km 12, Areia - PB. CEP: 58.397-000. Autor para correspondência: email: meduardo freire@hotmail.com

3 Técnica em Zootecnia pelo Instituto de Assistência Técnica e Extensão Rural (EMATER) - RN.

${ }^{4}$ Docente da Universidade Federal da Paraiba. Campus II - Rodovia BR 079 Km 12, Areia - PB. CEP: 58.397-000. Autor para correspondência: albericio@uol.com.br

${ }^{5}$ Mestre pelo Programa de Pós-graduação em Zootecnia do CCA/UFPB - Areia, PB. 


\title{
Resumo
}

A caatinga é um bioma unicamente brasileiro, com vegetação peculiar, predominante em regiões do Semiárido nordestino. É rica em espécies forrageiras em seus estratos arbóreo, arbustivo e herbáceo. A maioria das espécies vegetais participa significativamente da alimentação dos ruminantes, sendo que as gramíneas e dicotiledôneas herbáceas perfazem acima de $80 \%$ da dieta desses animais durante o período chuvoso. Este, que dura cerca de quatro meses, comumente há oferta de forragem, porém à medida que começa o período subseqüente, o seco, a disponibilidade de folhas secas decorrentes das espécies caducifólias aumenta e se tornam cada vez mais importantes para os animais, principalmente aos caprinos. Estrategicamente, as espécies lenhosas são fundamentais no contexto de produção e disponibilidade de forragem no Semiárido brasileiro, principalmente na época seca. O grande desafio da pecuária no Semiárido é utilizar os recursos da caatinga preservando sua sustentabilidade. Várias alternativas de exploração têm sido propostas, porém quase todas apresentam grandes limitações em decorrência da alta variabilidade temporal e espacial da acumulação da fitomassa, que está diretamente dependente das condições da precipitação da região.

Palavras-chave: bioma, caprinos, ovinos, forragem, semiárido.

\section{Climate characteristics and stress of water effects in native plants of caatinga}

\begin{abstract}
The caatinga is a uniquely Brazilian biome, with vegetation peculiar, predominantly in regions of the Semiarid. It is rich in forage species in their structure woody, shrubby and herbaceous. Most plant species participate significantly in ruminant feed, and the grasses and forbs along make up over $80 \%$ of the diet of these animals during the rainy season. This, which lasts about four months, there is often forage offer but when begin the subsequent
\end{abstract}


period, the dry period, the availability of leaves arising from deciduous species increases and becomes increasingly important for animals, especially the goats. Strategically, woody species are critical in the context of production and forage availability in semiarid Brazil, especially in the dry season. The big challenge is to use livestock in semi-arid preserving the resources of its sustainability. Several alternatives have been proposed to exploit, but almost all have major limitations due to the high temporal and spatial variability of accumulation of biomass, which is directly dependent on the conditions of precipitation in the region.

Keywords: biome, goats, sheep, forage, semiarid

\section{INTRODUÇÃO:}

O Nordeste brasileiro abrange uma área de $1.558 .196 \mathrm{~km}^{2}(18,3 \%$ da área total), com uma população de 51.609 .027 habitantes $(28,05 \%$ da população brasileira), segundo o IBGE (2006). A região Semiárida do Brasil abrange $982.563 \mathrm{~km}^{2}$ (Brasil, 2005a), com 89,46\% localizados na região Nordeste, onde oito dos nove estados têm pelo menos $45 \%$ de sua área incluída no Semiárido.

A região Semiárida brasileira é caracterizada por apresentar uma alta variabilidade ambiental (solo, clima, vegetação e relevo) e formando um mosaico de ecossistemas únicos, que demandam conhecimento específico para seu manejo (Menezes et al., 2005). Esses fatores ambientais são responsáveis pela vegetação denominada caatinga, adaptada à distribuição da precipitação e edáficas, formada em sua maioria por xerófitas caducifólias.

Botanicamente, tal bioma constitui-se um complexo vegetacional muito rico em espécies lenhosas caducifólias e herbáceas anuais. A maior dificuldade na classificação das caatingas está relacionada com a variação de sua fisionomia resultante da interação principal de solo e clima, além da interferência antrópica. A heterogeneidade espacial da vegetação e das condições ambientais é uma das principais características das zonas áridas e 
SOUZA, M.T.C. et al. Caracterização climática e o efeito do estresse hídrico sob as plantas nativas da caatinga. PUBVET, Londrina, V. 8, N. 1, Ed. 250, Art. 1655, Janeiro, 2014.

Semiáridas, atribuídas a processos geomorfológicos da paisagem (Schlesinger et al., 1990).

As caatingas apresentam inúmeras tipologias, que se manifestam como produtos da evolução, traduzidas em adaptações e mecanismos de resistência ou tolerância às adversidades climáticas (Pereira, 2000). Essa flora demorou milênios de anos de evolução para atingir o estado atual de adaptação e para adquirir as propriedades fisiológicas. Garantir a sobrevivência da caatinga nativa, em diferentes pontos do nordeste significa preservar um valorosíssimo patrimônio de recursos naturais (Duque, 1980).

Outra característica marcante da região Semiárida é a alta temperatura, que pode afetar diretamente a qualidade da forragem disponível. As altas temperaturas promovem rápida lignificação da parede celular, acelerando a atividade metabólica celular, resultando em diminuição do pool de metabólitos no conteúdo celular. Eles também promovem a rápida conversão dos produtos fotossintéticos em componentes da parede celular (Van Soest, 1965). Segundo Silva et al. (2011) a composição bromatológica das espécies da caatinga herbácea varia dependendo do estado de conservação da área e da época do ano (estação seca ou chuvosa). O pool de espécies herbáceas na estação chuvosa apresenta indicadores qualitativos que permitem classificar essas plantas como aptas para o consumo pelos animais ruminantes, já adaptados ao Semiárido.

Uma característica marcante da região, além do seu complexo vegetacional, é a alta variabilidade hídrica interanual e mensal. Segundo Andrade et al. (2006), a precipitação média mensal do mês de Janeiro variou de $10 \mathrm{~mm}$ em 1993 a 180mm em 2006 na região do Cariri paraibano.

Além de todas essas peculiaridades, historicamente, tal patrinônio nacional não tem recebido a valorização merecida, o que pode ter sido provocado pela cultura local, pelo desenvolvimento humano insatisfatório e pela ínfima ajuda do governo local com um grande contingente de excluídos, embora existam muitos casos de sucesso. Entretanto, tem sido tema das mais variadas reflexões e objeto de muitas ações de pesquisa. Outros Semiáridos do 
SOUZA, M.T.C. et al. Caracterização climática e o efeito do estresse hídrico sob as plantas nativas da caatinga. PUBVET, Londrina, V. 8, N. 1, Ed. 250, Art. 1655, Janeiro, 2014.

mundo são muito diferentes e alguns conseguiram mudar sua realidade de forma favorável. Por exemplo, o deserto norte-americano abriga estados economicamente fortes, alguns deles, como a Califórnia, com significativa participação da agricultura na geração de riquezas. Exemplo de sucesso ocorre também na Espanha e na Austrália, dentre outros (Queiroz e Malavasi, 2007).

Desse modo, é plausível afirmar que há muita riqueza a ser explorada nesse bioma. A vegetação e os microrganismos que ali habitam são fortes o suficiente para suportarem meses de seca a fio, podendo rebrotar e emergir com todo vigor nas primeiras chuvas, a ponto de se reproduzirem até a próxima época seca.

O objetivo dessa revisão é expandir o conhecimento técnico-científico de trabalhos já executados na caatinga, assim como divulgar a grande riqueza a ser explorada já existente no Semiárido paraibano.

\section{REVISÃO DE LITERATURA}

\section{CARACTERIZAÇÃO DO BIOMA CAATINGA}

O conceito técnico de Semiárido foi estabelecido a partir de uma norma da Constituição Brasileira de 1988, que no seu Artigo 159, institui o Fundo Constitucional de Financiamento do Nordeste (FNE). A norma constitucional manda aplicar no Semiárido $50 \%$ dos recursos destinados ao Fundo. A Lei 7.827 de 27 de setembro de 1989, regulamentando a Constituição Federal, define como Semiárido a região inserida na área de atuação da SUDENE, com precipitação pluviométrica média anual igual ou inferior a $800 \mathrm{~mm}$ (Silva, 2006).

Ao longo de sua história, teve outras denominações como "Sertão" e o "Nordeste das secas". Oficialmente, a primeira delimitação da região foi estabelecida em 1936, com o Polígono das Secas (Silva, 2006). O prolongamento do período seco anual eleva a temperatura local, caracterizando a aridez sazonal. De acordo com essa definição, o grau de aridez de uma região depende da quantidade de água proveniente da chuva 
SOUZA, M.T.C. et al. Caracterização climática e o efeito do estresse hídrico sob as plantas nativas da caatinga. PUBVET, Londrina, V. 8, N. 1, Ed. 250, Art. 1655, Janeiro, 2014.

(precipitação) e da temperatura que influencia a perda de água por meio da evapotranspiração potencial.

De acordo com a delimitação atual, o Semiárido abrange 1.133 municípios com uma área de 969.589,4 km², corresponde a quase $90 \% \mathrm{da}$ Região Nordeste (nos estados do Piauí, Ceará, Rio Grande do Norte, Paraíba, Pernambuco, Alagoas, Sergipe e Bahia); e mais a região norte de Minas Gerais. Com uma população de 21 milhões de pessoas, a região é caracterizada como um espaço cada vez mais urbano. Entre 1991 e 2000, a população total cresceu $8,62 \%$ mas o crescimento urbano chegou a $26 \%$; enquanto a população rural decresceu $8,16 \%$.

O Produto Interno Bruto (PIB) per capita do Semiárido em 2002 era de $R \$ 2.541,27$, bem baixo do valor médio da região Nordeste ( $R \$ 3.694,34)$ e menos da metade da média nacional de $R \$ 7.630,93$ (Brasil, 2005). A maioria dos municípios depende, cada vez mais, da transferência de recursos dos níveis federal e estadual, do repasse do Fundo de Participação dos Municípios e de outras verbas federais e estaduais para manter os serviços oferecidos a população.

De acordo com o Atlas do Desenvolvimento Humano no Brasil (2000), em $47,5 \%$ dos municípios do Semiárido brasileiro, um terço da população tem mais da metade de sua renda proveniente de transferências do governo, principalmente dos benefícios previdenciários tanto no espaço urbano como no espaço rural. A transferência de renda através de benefícios (bolsa família, auxílio maternidade, fome zero) não tem sido suficientes para melhorar os indicadores sociais da educação, saúde, habitação, trabalho, mortalidade infantil, elevada concentração de renda e baixo IDH.

Segundo Silva (2006), verifica-se que estão sendo formuladas três propostas ou alternativas para a realidade dessa região: combater as secas e os seus efeitos; aumentar a produção e a produtividade econômica na região, sobretudo com base na irrigação; e conviver com o Semiárido, combinando a produção apropriada com a qualidade de vida da população local. 


\section{CARACTERIZAÇÃO CLIMÁTICA}

Climaticamente, o Semiárido brasileiro caracteriza-se por clima quente e seco, com duas estações, a seca e a úmida, com pluviosidade situada nas isoietas de, aproximadamente, $300-800 \mathrm{~mm}$. A maior parte das chuvas se concentra em três a quatro meses dentro da estação da úmida, acarretando um balanço hídrico negativo na maioria dos meses do ano e elevado índice de aridez. Observam-se ainda temperaturas médias em torno de $28^{\circ} \mathrm{C}$, sem significativas variações estacionais (Araújo Filho et al., 1995).

O clima predominante na região Semiárida nordestina é do tipo BSw'h', conforme a classificação de Köppen, ou seja, tropical seco com a evaporação excedendo a precipitação, com ocorrência de pequenos períodos de chuvas sazonais. Outra característica importante da região é a imprevisibilidade das estações chuvosas, de maneira que a época em que são elevados os índices pluviométricos varia ano a ano, tornando-se difíceis às tomadas de decisão sobre o uso dos recursos desse ecossistema. Andrade et al.( 2010) afirmam que enquanto a temperatura, a radiação solar e os aportes de nutrientes nos ecossistemas do Semiárido variam relativamente pouco no ano, a precipitação comumente ocorre em eventos descontínuos, em forma de pulsos de curta duração (Noy-Meir, 1973).

Os pulsos de precipitação pluvial nas regiões Semiáridas podem acontecer de três formas distintas como mostra na figura 1: (a) amplamente separados, (b) agrupados, (c), com espaçamento intermediário. Entretanto, nos períodos chuvosos, os intervalos entre cada evento podem estimular os pulsos de crescimento da planta (Noy-Meir, 1973), e como conseqüência a recuperação dessas reservas. 
SOUZA, M.T.C. et al. Caracterização climática e o efeito do estresse hídrico sob as plantas nativas da caatinga. PUBVET, Londrina, V. 8, N. 1, Ed. 250, Art. 1655, Janeiro, 2014.
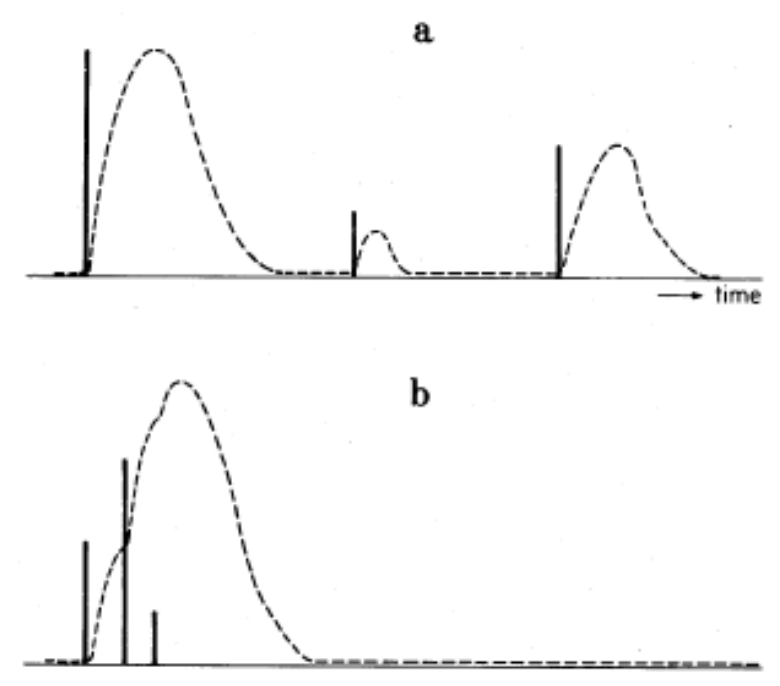

c

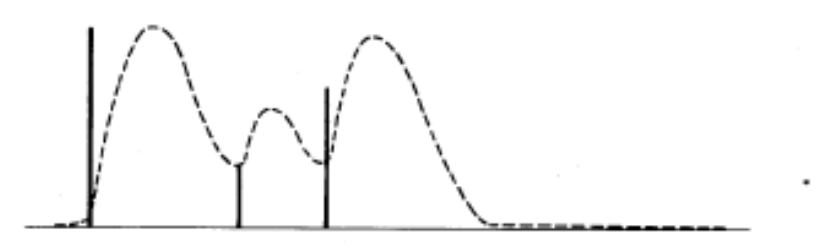

Figura 1 - Sistema de resposta aos pulsos de entrada: (a) amplamente separados, (b) agrupados, (c), com espaçamento intermediário Fonte: Noy-Meir (1973)

Andrade et al. (2005), afirmam que esses ambientes Semiáridos são caracterizados pela alta variabilidade das chuvas, onde os eventos são constituídos por pulsos de precipitação. Deste modo o conhecimento do sincronismo e da amplitude das chuvas vem a ser fundamental para o estudo da dinâmica do ecossistema.

\section{SOLOS}

Os solos das regiões áridas e Semiáridas apresentam geralmente baixos teores de matéria orgânica, sendo a produtividade dependente dos níveis de fertilidade natural e da possibilidade de mantê-los através da ciclagem de nutrientes (Sampaio et al., 1995). O solo desempenha um papel importante na variação fisionômica da caatinga, na formação das paisagens, como suporte 
SOUZA, M.T.C. et al. Caracterização climática e o efeito do estresse hídrico sob as plantas nativas da caatinga. PUBVET, Londrina, V. 8, N. 1, Ed. 250, Art. 1655, Janeiro, 2014.

mecânico e no fornecimento de nutrientes e água, essencial para o estabelecimento e desenvolvimento das plantas.

Segundo Melo (2004), há uma relação estreita entre o solo e a vegetação, já que alterações na vegetação podem afetar os atributos físicos e químicos do solo, como também, alterações feitas ao solo, provocar efeito significativo na vegetação. Segundo Sampaio (2010) a variabilidade dos solos advém, principalmente, do efeito diferencial da erosão geológica, descobrindo camadas distintas, até o limite da exposição das rochas, formando lajedões e os pavimentos recobertos por rochas.

Sá et al., 2004, ressaltaram que os Estados do Ceará e da Paraíba tem as maiores áreas, em termos percentuais, com problemas de degradação no nível severo, seguidos de perto pelos Estados de Pernambuco e Bahia. O nível de degradação ambiental severo aparece principalmente nas áreas dos Estados onde se encontram os solos do tipo Luvissolos (antigo Bruno-não-cálcico). 0 nível de degradação ambiental acentuado está mais relacionado às áreas de solos Litólicos, ou seja, solos mais recentes e em fase de desagregação da rocha que the deu origem.

\section{EFEITO DO ESTRESSE HÍDRICO SOBRE O CRESCIMENTO DAS}

\section{PLANTAS}

O déficit de água no solo constitui o maior ponto de estrangulamento do processo produtivo agrícola e das pastagens em áreas do Brasil e do mundo, onde a precipitação seja escassa ou mal distribuída (Begg e Turner, 1976). Sendo assim, variações na disponibilidade de água no solo promovem diferenças no desenvolvimento do sistema radicular dos vegetais, afetando a absorção de nutrientes, devido às alterações no sistema radicular para exploração de maior volume de solo. Além disso, os sistemas radiculares das plantas cultivadas são mais sensíveis e se alteram mais freqüentemente por mudanças nos níveis de água do solo, do que por qualquer outro fator relevante (Das e Jat, 1977). 
SOUZA, M.T.C. et al. Caracterização climática e o efeito do estresse hídrico sob as plantas nativas da caatinga. PUBVET, Londrina, V. 8, N. 1, Ed. 250, Art. 1655, Janeiro, 2014.

Segundo Taiz e Zeiger (1991), o estresse hídrico acarreta mudanças fisiológicas não somente no sistema radicular. Essas mudanças consistem também na redução da produção da área foliar, fechamento dos estômatos, aceleração da senescência e abscisão das folhas. Para McCree e Fernandez (1989), quando expostas ao déficit hídrico, as plantas, freqüentemente, exibem respostas fenológicas que resultam de modo indireto na conservação da água no solo como se estivessem economizando para períodos posteriores.

\section{COMPLEXO VEGETACIONAL}

A caatinga é caracterizada por uma vegetação caducifólia espinhosa e representa a formação florestal típica das regiões Semiáridas do Nordeste do Brasil, sendo uma mistura de estratos herbáceo, arbustivo e arbóreo de pequeno porte, de folhas caducas e pequenas, tortuosas, espinhentas e de elevada resistência às estiagens (Souto et al., 2007). Apresenta uma grande biodiversidade com espécies de portes e arranjos fitossociológicos variados, que a torna complexa, onde pouco se conhece sobre a sua dinâmica (Souto, 2006).

Com base na interação entre vegetação e solo, a região pode ser dividida nas seguintes zonas: domínio da vegetação hiperxerófila, domínio da vegetação hipoxerófila, ilhas úmidas, agreste e área de transição (tabela 1) Sá et al. (2004.)

Tabela 1 - Compartimentação ambiental do Semiárido Brasileiro

\begin{tabular}{lccccc}
\hline & $\begin{array}{c}\text { Vegetação } \\
\text { Hiperxerófi } \\
\text { la }\end{array}$ & $\begin{array}{c}\text { Vegetação } \\
\text { Hipoxerófil } \\
\text { a }\end{array}$ & $\begin{array}{c}\text { Ilhas } \\
\text { úmidas }\end{array}$ & $\begin{array}{c}\text { Agreste e } \\
\text { área de } \\
\text { transição }\end{array}$ & Total \\
\hline $\begin{array}{l}\text { Área em } \\
\mathrm{Km}^{2}\end{array}$ & 317.608 & 399.777 & 83.234 & 124.424 & $\begin{array}{c}925.0 \\
43\end{array}$ \\
\hline $\begin{array}{l}\% \\
\begin{array}{l}\text { Nordeste } \\
\%\end{array}\end{array}$ & 19,09 & 24,04 & 5,00 & 7,48 & 56,61 \\
Semiárido & 34,33 & 43,21 & 9,00 & 13,46 & $\begin{array}{c}100,0 \\
0\end{array}$ \\
\hline
\end{tabular}

Fonte: Sá et al. (2004) 
SOUZA, M.T.C. et al. Caracterização climática e o efeito do estresse hídrico sob as plantas nativas da caatinga. PUBVET, Londrina, V. 8, N. 1, Ed. 250, Art. 1655, Janeiro, 2014.

A vegetação nativa é extremamente adaptada às condições climáticas de semiaridez da região, estando muito atuante em toda a vida do homem da zona rural no tocante a alimentação humana e animal, com suas finalidades medicinais, frutífera, construção civil, melífera, dentre outras, além de sua principal função que consiste na manutenção e nutrição dos rebanhos situados na região.

Além disso, a vegetação da caatinga é rica e diversificada em espécies forrageiras, dentre elas Drumond (2000) destaca: o angico (Anadenanthera macrocarpa (Benth)), o pau-ferro (Caesalpinia ferrea Mart. ex. Tul.), a catingueira, a catingueira-rasteira (Caesalpinia microphylla Mart.), a canafistula (Senna spectabilis var. excelsa (Sharad) H.S.Irwine \& Barnely), o marizeiro (Geoffraea spinosa Jacq.), a jurema-preta (Mimosa tenuiflora (Willd.) Poiret), o sabiá (Mimosa caesalpinifolia (Benth.)), o rompe-gibão (Pithecelobium avaremotemo Mart.) e o juazeiro (Zizyphus joazeiro Mart.), entre as espécies arbóreas; o mororó (Bauhinia sp.), o engorda-magro (Desmodium sp.), a marmelada-de-cavalo (Desmodium sp.), o feijão-bravo (Capparis flexuosa L.), o matapasto (Senna sp.) e as urinárias (Zornia sp.), entre as espécies arbustivas e subarbustivas; e as mucunãs (Stylozobium sp.) e as cunhas (Centrosema sp.), entre as lianas e rasteiras. Destacam-se como frutíferas, o umbu (Spondias tuberosa Arruda), araticum (Annona glabra L., A. coriacea Mart., A. spinescens Mart.), mangaba (Hancornia speciosa Gomez), jatobá (Hymenaea spp.), juazeiro (Ziziphus joazeiro Mart.), murici (Byrsonima spp.), e o licuri (Syagrus coronata (Mart.) Becc.), que são exploradas de forma extrativista pela população local, sem qualquer técnica de cultivo. Essa forma de exploração tem levado a uma rápida diminuição das populações naturais dessas espécies vegetais, que estão ameaçadas de extinção (Drumond, 2000).

\section{POTENCIAL FORRAGEIRO DA CAATINGA}

O potencial de produção de matéria seca (MS) da vegetação da caatinga é resultante da parte aérea das plantas arbustivas e arbóreas e das folhas e 
ramos das espécies herbáceas, que juntos atingem cerca de $4.000 \mathrm{~kg} / \mathrm{ha} / \mathrm{ano}$ (Araújo Filho et al., 2002). Mesmo reconhecendo esse potencial, é importante ressaltar que nem toda forragem produzida fica disponível para o animal, além de que ocorre grande variação dessa produção em função de fatores ambientais como estação do ano (chuvosa ou seca) e a ação antrópica, especialmente quanto à forma e à intensidade de uso dos recursos forrageiros. Normalmente, a maior disponibilidade de forragem ocorre na estação chuvosa e é fornecida pelo estrato herbáceo. À medida que se caracteriza o período de estiagem, as folhas senescentes das plantas lenhosas são incorporadas à dieta dos animais e podem representar o único recurso forrageiro disponível, em alguns tipos de caatinga (PEREIRA FILHO E BAKKE, 2010).

No Semiárido brasileiro a caatinga é uma das principais fontes de forragens para 0 rebanho caprino durante 0 ano todo, principalmente para aqueles rebanhos criados extensiva ou semi-intensivamente. Porém, a caatinga apresenta uma dinâmica de produção de fitomassa variável de acordo com as épocas do ano (Figura 2).

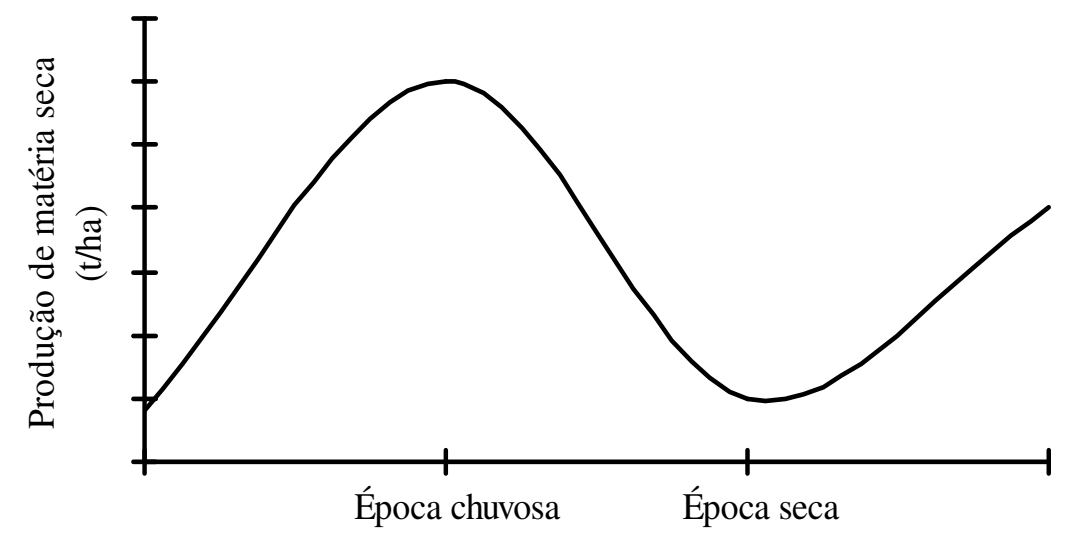

Figura 2. Disponibilidade de forragens da caatinga durante o ano.

Andrade et al. (2010) reportam que no início das chuvas, o estrato herbáceo nos sítios ecológicos da caatinga com maior potencial é dominado por gramíneas que completam seu ciclo fenológico nos primeiros 40 dias. Outras 
SOUZA, M.T.C. et al. Caracterização climática e o efeito do estresse hídrico sob as plantas nativas da caatinga. PUBVET, Londrina, V. 8, N. 1, Ed. 250, Art. 1655, Janeiro, 2014.

espécies, como algumas dicotiledôneas, desaparecem em menor espaço de tempo. Segue-se, então, uma substituição da dominância que passa a ser exercida por dicotiledôneas herbáceas anuais. Porém, Formiga et al. (2012) estudando a disponibilidade de algumas espécies herbáceas na caatinga encontrou uma modificação no estrato herbáceo pelo aumento das plantas indesejáveis, como o capim panasco (Aristida setifolia) que esteve presente em todos os períodos de avaliações com participação variando entre 15 a 55\%, podendo ainda ser destacado por ser uma espécie de baixo valor nutricional, comportamento semelhante teve a malva (Malvastrum coromandelianum) do grupo das dicotiledôneas que também esteve presente durante o período de baixa precipitação pluviométrica. Um aspecto que deve ser considerado é que tanto o capim panasco quanto a malva são espécies indicadoras de áreas degradadas.

Santos (2006), avaliando a disponibilidade de fitomassa do estrato herbáceo de uma caatinga raleada no Sertão da Paraíba, obteve 2252,8kg de matéria seca para gramíneas e $1746,4 \mathrm{~kg}$ para as dicotiledôneas herbáceas, totalizando $3999,2 \mathrm{~kg} / \mathrm{ha}$. Em termos de composição florística, as gramíneas representaram $56,32 \%$ do total e as dicotiledôneas $43,68 \%$ do total. Carvalho Júnior (2008) avaliou em três momentos a disponibilidade total de matéria seca do estrato herbáceo de uma caatinga raleada em Patos/PB e observou aumento entre a primeira e a segunda avaliação, ocorridas respectivamente em 28/05/07 e 09/07/07, e queda no final do experimento, em 06/08/07 (Tabela 2). O aumento de matéria seca do início para o meio do período experimental pode estar associado aos dados de pluviosidade que foi de $71 \mathrm{~mm}$ no mês de maio, $0,0 \mathrm{~mm}$ em junho e de apenas $10 \mathrm{~mm}$ em julho.

As plantas monocotiledôneas tem como característica o sistema radicular fasciculado das, que é superficial. O sistema radicular pivotante das dicotiledôneas são capazes de buscar água e outros nutrientes nas camadas mais profundas do solo, o que Ihes permite um ciclo biológico mais longo e, 
SOUZA, M.T.C. et al. Caracterização climática e o efeito do estresse hídrico sob as plantas nativas da caatinga. PUBVET, Londrina, V. 8, N. 1, Ed. 250, Art. 1655, Janeiro, 2014.

por conseqüência, manterem o valor nutritivo mais elevado ao longo do ano (ou da estação seca).

Tabela 2. Disponibilidade de matéria seca das gramíneas, dicotiledôneas e composição florística do estrato herbáceo de uma caatinga raleada, em Patos/PB

\begin{tabular}{lccccc}
\hline & \multicolumn{2}{c}{ Matéria seca $(\mathrm{kg} / \mathrm{ha})$} & \multicolumn{2}{c}{ Composição florística (\%) } \\
\cline { 2 - 5 } Época do ano & Gramíneas & Dicotiledôneas & Total & Gramíneas & Dicotiledôneas \\
\hline Início & 1102,9 & 1759,5 & 2862,4 & 38,5 & 61,5 \\
$(28 / 05 / 2007)$ & & & & & \\
Meio $(09 / 07 / 2007)$ & 1417,9 & 1929,9 & 3347,8 & 42,4 & 57,6 \\
Final (06/08/2007) & 1494,8 & 236,8 & 1731,6 & 88,6 & 11,4 \\
\hline
\end{tabular}

Fonte: Carvalho Júnior (2008)

Por isso, a vegetação lenhosa constitui a mais importante fonte de forragem para o forrageamento dos rebanhos dos sertões nordestinos, compondo em até $90 \%$ a dieta de ruminantes domésticos principalmente na época seca (Peter, 1992), sendo que a manipulação de árvores e arbustos forrageiros, técnica necessária para melhoria da qualidade e aumento da produção de forragem, requer o conhecimento adequado das características de produção de fitomassa e o valor nutritivo das plantas. Como estes fatores se relacionam com o ciclo fenológico das plantas, servem também como base para determinação da melhor época de utilização (Araújo Filho e Carvalho, 1997).

Além disso, as espécies nativas do Semiárido destacam-se pela resistência à seca, por fazerem parte dos sistemas pecuários, e por apresentarem em sua composição alto nível protéico, fornecendo produtos como madeira, frutos e túberas (Araújo et al., 2001).

\section{CONSIDERAÇÕES FINAIS}

Conhecer $o$ potencial forrageiro da caatinga e estudar as melhores formas da sua utilização na alimentação dos animais constitui ainda 
SOUZA, M.T.C. et al. Caracterização climática e o efeito do estresse hídrico sob as plantas nativas da caatinga. PUBVET, Londrina, V. 8, N. 1, Ed. 250, Art. 1655, Janeiro, 2014.

um grande desafio a ser enfrentado. Assim, conhecer melhor o comportamento dessas espécies em meio às condições de estresse hídrico, além do pisoteio animal sobre algumas espécies que compõem o estrato herbáceo é imprescindível, pois quando é feita uma má distribuição dos animais nos piquetes para pastejo, algumas dessas espécies herbáceas tendem a desaparecer e, conseqüentemente pode haver uma degradação/desertificação dessas áreas de caatinga. Além disso, deve-se buscar estratégias de utilização dos recursos forrageiros da caatinga, sempre numa perspectiva de sustentabilidade econômica e ambiental, de forma que possa contribuir para a manutenção do homem no meio rural, com melhorias para a sua convivência familiar.

\section{REFERÊNCIAS:}

ANDRADE, L. A.; PEREIRA, I. M.; LEITE, U. T.; BARBOSA, M. R. V. Análise da cobertura de duas fitofisionomias de caatinga, com diferentes históricos de uso, no município de São João do Cariri, Estado da Paraíba. Cerne, v.11, n.3, p.253-262, 2005.

ANDRADE, A.P. de; SOUZA, E.S. de; SILVA, D.S. da; et al. 2006. Produção animal no bioma caatinga: paradigmas dos "pulsos-reservas". In: REUNIÃO ANUAL DA SOCIEDADE BRASILEIRA DE ZOOTECNIA, 43. Anais de Simpósios..., 2006. João Pessoa.

ANDRADE, A.P., SANTOS, E.M.; SILVA, D.S., COSTA, R.G., XIMENES, L.J.F. 2010. Variabilidade sazonal da oferta e demanda de forragem no semiárido brasileiro. IN. XIMENES, LJ.F et al. (Eds.) Ciência e Tecnologia na Pecuária de Caprinos e Ovinos. Fortaleza: Banco do Nordeste do Brasil, 2010. p.23-69.

ARAÚJO FILHO, J. A.; CARVALHO, F. C.; GARCIA, R.; SOUSA, R. A. Efeitos da manipulação da vegetação lenhosa sobre a produção e compartimentalização da fitomassa pastável de uma caatinga sucessional. Revista Brasileira de Zootecnia, v. 31, n. 1, p. 11-19, 2002.

ARAÚJO FILHO, J.A. Manipulação da vegetação lenhosa da caatinga para fins pastoris. Sobral: EMBRAPA-CNPC, 1995. 18p. (EMBRAPA-CNPC. Circular Técnica, 11)

ARAÚJO FILHO, J.A.; CARVALHO, F.C. Desenvolvimento sustentado da caatinga. Sobral, CE: EMBRAPA-CNPC, 1997, 19p, (EMBRAPA-CNPC, Circular Técnica, 13).

ARAÚJO, G.G.L., ALBUQUERQUE, S.G. de, GUIMARÃES FILHO, C. Opções no uso de forrageiras arbustivo-arbóreas na alimentação animal no semi-árido do Nordeste. In: SISTEMAS AGROFLORESTAIS PECUÁRIOS: opções de sustentabilidade para áreas tropicais e subtropicais, Juiz de Fora, MG. Livro [Ed.] Carvalho, M.M., Alvim, M.J. e Carneiro, J.C. Juiz de Fora, MG: Embrapa Gado de Leite; Brasília: FAO, 2001. p.111-137.

ATLAS DO DESENVOLVIMENTO HUMANO NO BRASIL. Índice de Desenvolvimento Humando (IDH) - Indicadores e análises de desenvolvimento humano. 2000.

BEGG, J. E.; TURNER, N. C. Crop water deficits. Advances in agronomy. San Diego, New York: Academic Press, v. 28, p.161-217, 1976. 
BRASIL. Ministério da Integração Nacional/SDR. Relatório Final do Grupo de Trabalho Interministerial para Redelimitação do Semiárido Nordestino e do Polígono das Secas. Ministério da Integração Nacional, Brasília. 2005.

CARVALHO JÚNIOR, A. M. Efeito da Suplementação na Terminação de Caprinos F1 (Boer $x$ SRD) em Pastagem Nativa do Semi-Árido Paraibano. Dissertação (Mestrado) - Universidade Federal de Capina Grande, Patos - PB, 2008.

DAS, D. K.;JAT, R. L. Influence of three soil-water regimes on root porosity and growth of our rice varieties. Agronomy Journal . 69: p.197-200,1977.

DUQUE, G. O Nordeste e as lavouras xerófilas 3a. edição Escola Superior de Agricultura de Mossoró, Fundação Guimarães Duque - Conselho nacional de desenvolvimento Científico e tecnologia - programa do trópico semiárido Coleção Mossoroense v. CXLIII 1980 p. 316.

DRUMOND M. A., KIILL L. H. P., LIMA, P. C. F., OliVeirA M. C., OliVeirA, V. R., ALBUQUERQUE, S. G., NASCIMENTO, C. E. de S., CAVALCANTI J. Estratégias para o Uso Sustentável da Biodiversidade da Caatinga. Acesso online em 26 de Março de 2012: http://www.biodiversitas.org.br/caatinga.

FORMIGA, L. D. A. S.; PEREIRA FILHO, J. M.; SILVA, A. M. A.; OliVEIRA, N. S.; SOARES, D. C.; BAKKE, O. A. Forage supply in thinned Caatinga enriched with buffel grass (Cenchrus ciliaris L.) grazed by goats and sheep. Acta Scientiarum. Animal Sciences. v. 34, n. 2, p. 189-195, 2012.

INSTITUTO BRASILEIRO DE GEOGRAFIA E ESTATÍSTICA (IBGE). Censo Agropecuário. 2006. http:/www.ibge.gov.br. Consultado em 16 de Outubro de 2010.

MELO, M.S. Florística, fitossociologia e dinâmica de duas florestas secundárias antigas com histórias de usos diferentes no Nordeste do Pará-Brasil. 2004, 116f. Dissertação (Mestrado em Recursos Florestais). Escola Superior de Agricultura Luiz de Queiroz. Universidade de São Paulo. Piracicaba.

MENEZES, R. S. C.; GARRIDO, M. da S.; PEREZ M., A. M. Fertilidade dos solos no semiárido. In: XXX SIMPÓSIO BRASILEIRO DE CIÉNCIA DO SOLO. 30., 2005, Recife. Anais... Recife: SBCS, 2005. CD-ROM.

MCCREE, K.J.; FERNANDEZ, C. J. Simulation model for studyng physiological water stress responses of whole plants. Crop Scienc, v.29, p. 353-360. 1989.

NOY-MEIR, I. 1973. Desert ecosystems: environment and producers. Annual Reviews Ecology. Annual Review of Ecology and Systematics, v. 4 25-51p.

PEREIRA FILHO, J. M.; BAKKE, O. A. Produção de forragem de espécies herbáceas da Caatinga. In: GARIGLIO, M. A.; SAMPAIO, E. V. S. B.; CESTARO, L. A.; KAGEYAMA, P. Y. (Org.). Uso sustentável e conservação dos recursos florestais da Caatinga. Brasília: Serviço Florestal Brasileiro, 2010. p. 145-159.

PEREIRA, I.M. Levantamento florístico do estrato arbustivo-arbóreo e análise da estrutura Fitossociológica de ecossistema de caatinga sob diferentes níveis de antropismo. 2000, 70f. Dissertação (Mestrado)-Universidade Federal da Paraíba. Areia (PB), 2000.

PETER, A. M. B. Composição botânica e química da dieta de bovinos, caprinos e ovinos em pastoreio associativo na caatinga do semiárido de Pernambuco. Recife - PE: Universidade Federal Rural de Pernambuco, 1992. 86p. Dissertação (Mestrado em Zootecnia). Universidade Federal Rural de Pernambuco, 1992.

QUEIROZ, M. A.; MALAVASI, A. Plano Diretor do INSA. 2007. 73p. Disponível em: <www.insa.gov.br. $>$. Acesso em: 5 de junho de 2011. 
SÁ, I.B., RICHÉ, G.R., FOTIUS, G.A.As paisagens e o processo de degradação do semiárido nordestino In: Biodiversidade da Caatinga: áreas e ações prioritárias para a conservação. Brasilia: MMA-UFPE; Brasília, DF: 2004. p.17-36.

SAMPAIO, E. V. S. B.; SALCEDO, J. H.; SILVA, F. B. R. Fertilidade de Solos do semiárido do Nordeste. In: Reunião Brasileira de Fertilidade do Solo e Nutrição de Plantas, 21., 1995, Petrolina. Anais... Petrolina: SBCS, p.51-71, 1995.

SAMPAIO, E. V. de S. B. Características e potencialidades. In: Uso sustentável e conservação dos recursos florestais da caatinga. Gariglio et al. Brasília: Serviço Florestal Brasileiro, p.29-42, 2010.

SANTOS, E. M. Desempenho produtivo e exigências de energia e proteína de cordeiros em pastejo na caatinga, submetidos a diferentes níveis de suplementação. Dissertação (Mestrado) - Universidade Federal de Campina Grande, Patos-PB, 2006.

SCHLESINGER, W. H.; REYNOLLDS, J. F.; CUNNINGHAM, G. L.; HUENNEKE, L. F.; JARRELL, W. M.; VIRGINIA, R. A.; WHITFORD, W. G. Biological feedbacks in global desertification. Science, 247 (4946): 1043-10-48, 1990.

SILVA, R. M. A. Entre o Combate e à Convivência com o Semiárido: transições paradigmáticas e sustentabilidade do desenvolvimento. Tese de Doutorado. Centro de Desenvolvimento Sustentável. UnB. Brasília, 2006.

SILVA, D. S.; NADRANDE, M. V. M; ANDRADE, A. P.; CARNEIRO, M. S. S.; OlIVEIRA J. S. Bromatologic composition of the herbaceous species of the Northeastern Brazil Caatinga. Revista Brasileira de Zootecnia v.40, n.4, p.756-764, 2011.

SOUTO, P. C.; SOUTO, J. S.; SANTOS, R. V. dos; SALES, F. das C.; LEITE, R. de A.; SOUSA, A. A. de. Decomposição da serapilheira e atividade microbiana em área de caatinga. . In: XXXI Congresso Brasileiro de Ciência do Solo, 2007, Gramado. Anais... Gramado, SBCS, 2007. CDROM.

SOUTO, P. C. Acumulação e decomposição da serapilheira e distribuição de organismos edáficos em área de caatinga na Paraíba, Brasil. 2006. 150f. Tese (Doutorado em Agronomia) - Centro de Ciências Agrárias, Universidade Federal da Paraíba, Areia.

TAIZ, L.; ZEIGER, S. Plant physiology. Redwood City. The Benjamim Cummings Publishing Company, 1991,p.690.

VAN SOEST, P.J. Symposium on factors influencing the voluntary intake of herbage by ruminants: voluntary intake in relation to chemical composition and digestibility. Journal Animal Science, v.24, n.3, p.834-843, 1965. 